Journal of Economics, Finance and Accounting Studies (JEFAS)

ISSN: 2709-0809

DOI: 10.32996/jefas

Journal Homepage: www.al-kindipublisher.com/index.php/jefas

\title{
Analysis on Household Income to the Indigenous Aetas of Pampanga Philippines
}

\author{
Mhirone Jemel V. Dizon ${ }^{1} \square$ Fel Solomon V. Luzon ${ }^{2}$, Kaile Yuri L. Poblete ${ }^{3}$ and Marie Antoinette L. Rosette ${ }^{4}$ \\ ${ }^{1234}$ Business Economics Department, University of Santo Tomas, Philippines \\ $\square$ Corresponding Author: Mhirone Jemel V. Dizon, E-mail: mhironedizon@gmail.com
}

\begin{tabular}{ll}
\hline ARTICLE INFORMATION & ABSTRACT \\
\hline $\begin{array}{l}\text { Received: } 11 \text { October } 2021 \\
\text { Accepted: } 20 \text { November } 2021\end{array}$ & $\begin{array}{l}\text { Indigenous people (IPs) are the descendants of the inhabitants of a country or region. } \\
\text { Published: } 13 \text { December } 2021\end{array}$ \\
This study examines whether an indigenous group, specifically an Aeta community in \\
Pampanga, undergoes Urbanization or not. Migration has been a part of the Aeta's \\
history since the eruption of Mt. Pinatubo, which forced them to move out from their \\
original lands. Despite the Urbanization of the community, their culture and way of \\
KEYWORDS
\end{tabular}$\quad \begin{aligned} & \text { living remained the same and didn't change. The Aetas pass it on to their next } \\
& \text { generation, and due to this, they suffer from discrimination because of their way of } \\
& \text { living. To gather the needed data, the researchers reviewed various literature and } \\
& \text { studies to have an idea of how to construct the survey question based on LSMS and } \\
& \text { People, Migration, Employment, } \\
& \text { Total Household Income }\end{aligned} \quad \begin{aligned} & \text { Pampanga, a home of an Aeta community. By looking at the field site, it shows that } \\
& \text { development and accessibility of urban amenities are difficult for them since it was } \\
& \text { evident to the researchers that education and some necessities are insufficient. }\end{aligned}$

\section{Introduction}

Indigenous people are the descendants of the inhabitants of a country or a region (Balilla, 2013). Due to their distinct way of culture, they are usually discriminated against and being downed by many people. Due to this, the researchers would like to know if it is possible for indigenous people, specifically Aeta's, to be part of a community that is modernized and in which they would benefit from the development of an area by allowing them to have access to facilities and to experience advanced technology without affecting their normal culture and beliefs.

Urbanization is a process in which the industrial structure becomes increasingly oriented around secondary and tertiary industries instead of primary industries - the working population switches from agricultural to non-rural industrial and service occupations. It is beneficial for the economy, yet it affects our indigenous people in many ways by affecting their way of living. There are also changes in thinking patterns, way of living, behavior models, values, and culture (Chaolin, 2020).

When an area is being commercialized, there is usually land grabbing, and due to this, they migrate. The researchers would like to know if it is possible for indigenous people not to lose access to their land but be able to work due to the development that was done by private entities and public entities.

Urbanization is inevitable due to the fast-changing development happening in the world. As Urbanization takes place, people somehow forget that some people do not cope well in the fast-changing environment, such as the indigenous people living in rural areas. Over the years, we extinguished the Indigenous people as non-Christian tribes, cultural communities, hill tribes, national minorities, and tribal Filipinos (Ting Jr. et al., 2008). These people are stuck with their own traditional ways of living to the extent that they do not have proper access to basic amenities such as healthcare, water, and other basic technology until now. They are being forced to migrate to different locations threatening their most preserved cultural memento such as language, religion, cuisine, social habit, music, and arts (Ting et al., 2008). With the old traditional ways of living these, people would not develop but only adapt under their circumstances. In the recent study of Yang (2020), the research findings stated that crops and livestock are the only sources of food and income that are not nearly enough to sustain and secure their livelihood.

Copyright: (c) 2021 the Author(s). This article is an open access article distributed under the terms and conditions of the Creative Commons Attribution (CC-BY) 4.0 license (https://creativecommons.org/licenses/by/4.0/). Published by Al-Kindi Centre for Research and Development, London, United Kingdom. 
The independent variables are Urban amenities, Migration, and Employment, with a dependent variable of Total household income. These variables are all connected, affecting each other in both negative and positive relationships. As Urbanization takes place, some indigenous tribes are forced out of their homes, yet they still choose to migrate to non-urbanized rural areas since it is disadvantageous for them to adapt to the ways of living in urban cities because of cultural differences such as lifestyle and livelihood. With no choice to survive, indigenous people continue to look for a stable source of income since most of their population still relies on crops and livestock for a living. Accessible urban amenities such as clean water, health, and basic technology are other variables connected to the other three variables. As development takes place, access to these basic needs is necessary, especially to the indigenous people who are the most affected by fast-changing Urbanization.

The researchers wanted to know more about the matter. The Aeta community, being intact in preserving their culture, shows us that they have a strong foundation of the traditions and beliefs that they treasure. Adapting to different cultures could change a person, but concerning the Aeta community, they are flexible enough to get used to different cultures around them, especially since they are the ones who adjust because they are the ones who migrated. And even though they do not adopt different cultures in their ways of living, they still managed to continue and instill their practices in their own culture.

Apart from the Mt. Pinatubo Eruption in 1991 that led the Aeta Community to relocate, the decision of Indigenous people to migrate is mainly driven by economic considerations, as per Samuel Nii Ardey Codjoe (2006). In addition, another factor considered by the indigenous people when it comes to migration is improvement in the community through education. Rogayan (2019) conducted a study wherein Aeta students residing in an Urban Area for Education opted to do so to get a degree and help their families by getting a job. Aside from that, the respondents in the interview also wanted to share the knowledge they obtained in school with their fellow Aetas who did not have the opportunity to attend school. Considering all of the mentioned factors of migration, the researchers would also want to know the decision making such as choosing a place to migrate to and if there are other reasons for doing so.

According to $\mathrm{Fa}$ et al. (2020), indigenous people have a significant role in decision-making processes that could affect their lands since they inhabit and build a community within the area. When it comes to land occupation, one major challenge that most indigenous people encounter is the concept of "land grabbing," in which the indigenous people lose access to their land. The said land will be turned into a commercialized area which as a result, the most viable option for the community is to migrate (McDonell, 2017). All things considered, one of the researchers' objectives is to establish a possible development plan in the rural community and, at the same time, not harm the culture of the Aeta community would be possible.

Having three hundred million indigenous peoples in over seventy countries, with 14 million of them in the Philippines, confusion arises when it comes to identity and rights resulted in the construction of a policy called the Indigenous Peoples Rights Act in 1997 or also known as the Republic Act No. 8371 and the National Commission of Indigenous Peoples (NCIP). It took a decade for this institution to address the issue regarding guidelines and regulations. With that, numerous opportunities towards the leverage of cultural communities and ancestral domain encroachment were let go (Domingo and Manejar, 2020).

The significance of this study will benefit society, especially if some people have no knowledge of how indigenous communities adapt to rapid Urbanization. The study's findings elaborate on how indigenous communities cope with the changes and developments in society. Researchers and students alike will find this study beneficial for future studies that will elaborate on the culture and tradition of the indigenous communities further.

\subsection{Conceptual Framework}

Based on the discussion of the variables below, Total Household Income has a positive relationship with Urban Amenities, Migration, and Employment. Urbanization increases the employment rate due to the addition of establishments to an area. It also leads to more migrants entering the region. However, there would also be some locals that would leave due to the development. Moreover, there would be an improvement to the Urban Amenities due to having access to amenities and the market. All of the aforementioned factors may lead to an increase in income.

\subsection{Simulacrum}

Supported by the Review of Related Literature, it showed that Urban Amenities, Migration and Employment have a positive relationship with Total Household Income. For the measurement of Urban Amenities, the number of appliances that one household has will be used. This would allow the researchers to be able to measure their advancement in terms of development. For the measurement of Migration, Remittances that migrants give to their families left behind would be measured to know the difference in the salary in rural and urban areas and measure its impact in one household. For the measurement of employment, the number of working hours would be used to know how many hours they usually work. 


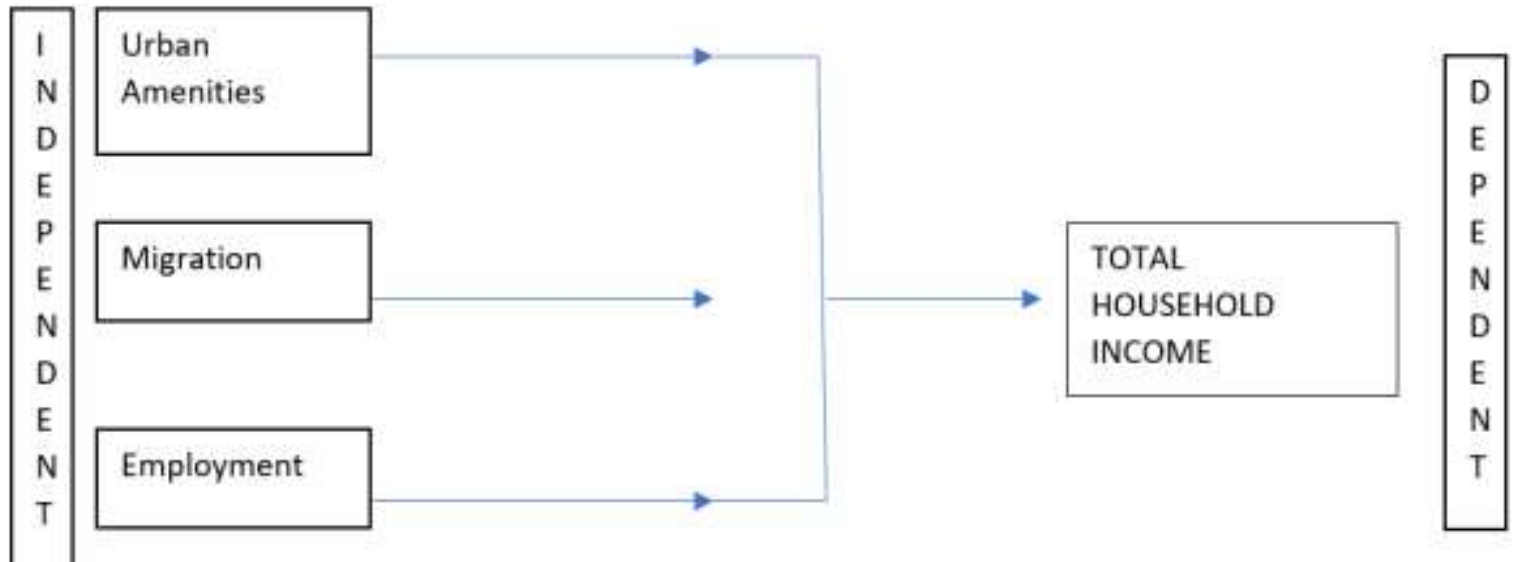

Figure 1.1: Illustration of the Research Simulacrum

\section{Literature Review}

This chapter discusses the variables that the researchers used for the study. This would give an in-depth analysis of the terms being used and the relationship of the dependent and independent variables through a literature review of other researchers.

\subsection{Indigenous people of the Philippines - Aeta}

According to De Vera (2007), indigenous people represent almost $14 \%$ of the country's population. They are one of the poorest and most disadvantaged social groups. They have a higher rate of morbidity, mortality, malnutrition, illiteracy, unemployment, and the incidence of poverty is much higher in them compared to the rest of the nation.

In addition, according to Ballila (2013), indigenous people are the descendants of the inhabitants of a country or region. These minority groups have a strong desire to maintain their tradition and culture and even pass them on to their future generations. One of the most well-known indigenous groups in the Philippines is the Aetas which can be found in different parts of Luzon and Visayas. One group that is being studied least is the Aeta Magbukun which maintained a primarily traditional hunter-gatherer lifestyle. Due to the lack of social services and high poverty rate, indigenous groups keep on migrating away from their traditional lands due to the increased economic activity and non-encroachment of non-Aeta on traditional lands, which puts the Aetas in danger threatened (Balilla, 2013).

\subsection{Indigenous people's culture}

Culture is one of the most valuable things that indigenous people preserve, such as language, religion, cuisine, social habits, music, and arts. Through the years of development, they have encountered political, social, and cultural inroads of colonization, which led them to isolate themselves amongst the majority of the Filipinos and consider themselves different (Ting et al., 2008). Many lived in plains and mountains where they were freely living and preserving their culture. However, as Urbanization takes place, they are forced to move to forest areas where most of these people become poor and landless while their cultures and practices are threatened (Ting Jr. et al., 2008).

Administrations began to create policies for the indigenous people since President Fidel Ramos declared Republic Act No. 8371 (an act to recognize, protect and promote the rights of indigenous cultural communities/indigenous peoples, creating a national commission on indigenous peoples, establishing implementing mechanisms, appropriating funds therefor, and for other purposes.) producing programs and projects to help and protect the rights of the indigenous people living in the country.

Projects and programs such as crop diversification are being implemented to prioritize those indigenous people who do not own land. They were given a fair size of acres of land to start cultivating crops, and basic infrastructure such as electricity and piped water, schools, and medical centres were being provided (Aziz, 2012).

Even though there is rapid technological advancement, Aetas can adjust to these challenges through foraging, livestock and poultry production, farming, agriculture, making and selling hard brooms, and being a recipient of the Pantawid Pampamilya Pilipino Program. The government, private sectors, and NGOs assist them by making them tour guides, recipients of different outreach activities; through this, they can sustain their needs. (Tindowen, 2012) 


\subsection{Usual challenges faced by Indigenous people}

Indigenous people in the Philippines and across the world tend to face difficulty in terms of economic and social factors such as accessibility, particularly regarding education, disaster vulnerable lands, and especially health services that are out of reach. These problems result in low productivity and low income of indigenous people. Aside from that, their homelands being far or inaccessible worsens the situation since the government has limited political power prohibiting a political system that could help and improve their situations (Tupoula, 2007).

According to Licen et al., (2012), an indigenous group of people in Zambales formed a non-formal education system called LAKAS (Lubos ng Alyansa ng mga katutubong Ayta sa Sambales) which covers different age groups and teachings are done by using the mother tongue. The organization's main goal is to attain empowerment and improve the welfare of its community. People within the community believe that obtaining literacy can improve the community welfare since being actively involved in politics and choosing the right candidate can be done by their people. According to them, Filipinos distrust politicians due to negative experiences in the past, and education serves as their power to protect their lands.

As stated by Anne-Marie Tupuola, indigenous people often migrate to urban areas, which adds to the challenges they face. Their usual struggles include unemployment, limited access to services, and housing. Aside from that, they are also discriminated against due to their language, identity, and culture, resulting in the loss of their heritage and values (Tupoula, 2007).

When it comes to obtaining education in an urban setting, a study done by Danilo V. Rogayan (2019) illustrated the dilemmas encountered by Aeta students. Verbal bullying, fear towards their teachers, language barriers, having low self-esteem, and academic pressure are some of the problems encountered by Aeta students. And even though they face such dilemmas or hardships, they are still eager to finish their studies to easily get a job that can help their families and bring and share their knowledge to fellow Aetas in the community.

\subsection{Total Household Income}

According to Albert et al. (2007), the importance of poverty measurement and analysis stems from the main goal of prioritizing the poor on the public policy agenda through measuring and analyzing the poverty level. Furthermore, it is acknowledged that the use of poverty data brought an advantage that helps manage poverty policies and programs more effectively. The Family Income and Expenditure Survey (FIES) is a monthly sample survey for the Statistics Bureau; its goal is to understand households' actual income and expenditures to provide a foundation for social and economic policies.

The research is derived from the methodology of Albert et al. (2007). The data was gathered from a survey from the 1997 FIES, utilizing the results from National poverty lines provided by the National Statistical Coordination Board (NSCB) in 1997. The research was also used in a similar FIES survey that seeks to gather information on the sources of income, the distribution of income, levels of spending patterns, and the degree of inequality among families.

In research conducted in Southern Malawi, a country in Africa, testing the null hypothesis to calculate the household income was done via interview. In order to acquire such information, the household head, the husband, is the only one being interviewed. Limiting the interview to one person per household has its fair share of advantages, such as reducing the time and expenses in conducting household surveys. Still, on the contrary, this appears to be detrimental to the data accuracy. In the study of Fisher et al. (2010), the result shows that obtaining and using figures such as the husband's estimated earnings of his wife's income is not a reliable set of data which could not produce statistically reliable results for poverty analysis and household income. It is not a reliable measurement due to the fact that only $6 \%$ of households wherein the husband's estimate and the wife's income matched (Fisher et al., 2010).

\subsection{Urban Amenities on Total Household Income}

According to Liao and Wang (2019), several studies prove the importance of access to urban amenities to the well-being of an individual, especially the rural-urban migrants. Social and cultural amenities such as the availability of hospital beds, telephone lines, and other basic urban amenities affect an individual's quality of life, leading to the intention to migrate.

Based on the data from American Community Surveys (ACS) ranging from 2011-2015, as the rich people's income rises, so does their desire for urban amenities, leading them to live in downtown urban areas to be closer to these urban areas amenities. The in-migration of higher-income individuals increases downtown rents, resulting in a financial externality for low-income residents in downtown urban areas (Couture et al., 2018).

The assessment of the sustainability of urban socio-ecological systems has grown significantly, with the additional interest generated by the fact that cities now shelter half of the world's population. In terms of providing good socioeconomic and 
environmental living conditions, urban areas face changing urban population sizes as well as increasing sustainability issues. Both challenges must be addressed in urban planning (Couture et al., 2018).

Many papers explore the causes of this growth in income inequality. One shows that rising incomes at the top of the distribution induced households to lower-income distribution to save less and consume a larger share of their income. Another demonstrates that the growing number of wealthy households in the United States explains some of the rapid rises in house prices and income in "superstar" cities with low housing supply elasticities, such as San Francisco, New York, and Boston (Couture et al. 2018).

According to Balilla et al. (2014), studies showed that every indigenous community member lacks access to health and hygiene needs. These include the hardware items and knowledge of correct hygiene behaviour. Insufficiency of health centres and professionals are also a problem of the indigenous community. The study of Balilla et al. (2014) proves that indigenous communities use medicinal plants and their own traditional ways of healing up to this day in the Philippines and in other countries. With this, it can be said that one of the unique strengths of indigenous people who live in a continuously urbanized environment is their general coping strategies (Gaillard, 2006). Another study by Phondani et al. (2013) stated that poor families tend to depend more on old traditional treatment methods on herbal medicine than rich and medium-class families. The lack of clean and accessible water is also a problem for the indigenous people since they only rely on rivers and springs, requiring them to walk for hours to fetch water so they can drink, cook, take a bath, and do their laundry. With the river drying, especially in warm seasons, indigenous people's water access and hygiene are compromised (Yang et al., 2020).

According to Zhang and Pryce (2019), there is a significant income disparity between residents living near the city center and those living in the suburbs. The research showed that income disparity is a serious factor that affects residents' quality of life in terms of access to modern technologies and transportation. The study also found out that poverty decentralization has resulted in greater disparities in access to employment and amenities in large urban areas between poor and non-poor households.

\section{Hypothesis \#1: Urban Amenities does not positively affect Total Household Income}

\subsection{Migration on Total Household Income}

The common view to exit from poverty is for rural households to migrate. (Howell, 2017) Studies show migration leads to a significant increase in rural incomes and decreased poverty rates in China's rural areas (Rozelle et al., 1999; Taylor et al., 2003; Zhu \& Luo, 2010). The remittances of the migrants are the most significant contributor to rural household income growth (De Brauw et al., 2002). Furthermore, studies show that ethnic minorities experience higher poverty rates since they are less likely to participate in the labor market and wage discrimination (Hannum \& Xie, 1998; Howell, 2013, 2016; Zang, 2008). A benefit of migration is the remittances migrants send to their relatives or community of origin. These remittances play a huge role in the development of economies, and due to this, it gains attention from policymakers and academics (Acosta, 2008; Adams \& Cuecuecha, 2010; Garip, 2014). In China, rural-urban migration increases average rural income irrespective of the ethnic status of a household, although considering ethnic heterogeneity exists (Howell, 2017).

Upon migration, the rural-urban migrants send remittances in different forms such as money, food, and clothing at a definite interval, commonly once a month. Their remittances improve the population's quality of life and well-being and increase people's happiness and satisfaction. Furthermore, the migrants execute development projects in their rural communities of origin, which leads to socioeconomic development. It also makes the private sector, government, and NGOs initiate development interventions to augment the contributions of rural-urban migration in the area (Ajaero \& Onokala, 2013).

People make migration decisions so they can maximize the expected present value of income. There is a significant effect of expected income differences on interstate migration. The elasticity of wages and migration is around 0.5. A negative effect of income in the current location on the probability of out-migration drives the relationship between wages and migration. Those who are earning good remain to stay in their location, yet those who earn bad tend to leave (Kennan \& Walker, 2011).

Openness to migration through increasing the range of skills and ideas in the host country has a role in accounting for crosscountry differences in income per capita. If Uganda were to adopt immigration policies that equalized immigration share to Ireland, its income per capita would increase by $70 \%$ in the long run (Ortega \& Peri, 2013).

To know the income gains from migration, one must compare the earnings of a migrant to what they would have earned in their home country before they migrated. Research conducted by Mckenzie et al. (2010) used a migrant lottery to provide an experimental measure of the income gains from migration. New Zealand has a quota of Tongans to immigrate each year, with this lottery used to choose amongst the excess number of applicants. They used a unique survey that allowed experimental estimates of the income gains from migration by comparing the income of migrants and those who applied to migrate. Simultaneously, they 
also surveyed individuals who did not apply for the lottery. Non-experimental methods can provide an unbiased estimate of the income gains due to migration. On account of non-experimental methods were found to state that the gains from migration are around 9 to 82 percent (Mckenzie et al., 2010).

Migration poses a challenge to the origin country, such as the risk of societal and political issues if migrants do not integrate sufficiently. However, according to Jaumotte et al. (2016), there are long-term benefits to migration, such as higher GDP per capita for recipient countries. High and low-skilled migrants can contribute to increasing GDP per capita. Low-skilled migrants are the case in which there is complementarity with the skills of natives. Complementarities are likely in fast-aging societies with rising education levels, where shortages occur, particularly in non-tradable low-skilled services, for which imports cannot substitute. The estimated impact of immigration on GDP per capita suggests that the fiscal benefits could be larger than typically calculated. Since static estimates of net fiscal gains, which calculate the difference between immigrants' tax and social security contributions and their recipients of social security benefits and government service, typically do not account for the indirect effects of immigration on the aggregate productivity of the economy (Jaumotte et al., 2016).

Large movements of people in West Africa are prominent. However, it is not due to the economic incentives, but rather, they are drawn to certain areas, larger cities, despite unemployment and poor living conditions there. An individual laborer will choose a location where he is best off--considering he changes residence and occupation. He will select the employment and region which will maximize his well-being--presuming that he will compare the income available at each place, adjusting the cost of moving, and even the culture and traditions in an area. An individual will not only compare two regions but all of the regions. Only a few data on estimating regional average wage are available, considering income or average returns to labor. An individual's decision to move is presumably based on the income he will earn with his occupation and training, not on the regional average income. In Ghana and elsewhere, the position of a given work is almost the same across all regions. But it differs in regional average income. Therefore, interregional migrations will lead to regions where there are high per capita income and high wages. Another determinant to be checked is the cost of moving. If transport cost is proportional to the distance moved, then migration is negatively related to distance. Two variables will be introduced, which show systematic differences in individual responses. First, education--measured by the percentage of adult males in the region who have attended school. Second, Urbanization--measured by the percentage of regional population residing in towns of 5000 or more. Ghanaians that have an education tend to be dissatisfied and move to cities without thinking about job opportunities. Therefore, there would be a large number of out-migrants if there were a large number of educated people in a region. On the other hand, Urbanization attracts people to migrate due to the need for people to have more advanced facilities (Amuakwa-Mensah et al., 2016).

\section{Hypothesis \#2: Migration does not positively affect Total Household Income}

\subsection{Employment on Total Household Income}

In Australia, its government is implementing actions such as policies for indigenous people living in remote areas because they suffer from high levels of unemployment in the community. And as per the suggestion of many people, such as the commentators who study this situation in the country, having a better educational opportunity for indigenous groups could improve socioeconomic status and employment opportunities. When it comes to socioeconomic problems, indigenous people are at a disadvantage compared to non-indigenous people, especially in securing employment that could lead to high mortality rates and illnesses that would result in a lower level of wealth. (Pearson and Daff, 2010)

With unemployment increasing across all ethnic and racial groups, especially the African Americans and the Hispanics in the year 2000, according to Conger et al. (2010), employment is reflected in family income levels. Race and gender are factors that influence economic circumstances which dictate family income. With unemployment being high, job availability or employment per se is a major factor affecting household income (Conger et al., 2010).

In terms of types of employment in relation to household income, those having a temporary job tend to earn lower. In that case, negative consequences would occur to household income. Having fewer working hours would result in fewer earnings. When it comes to fixed-term employment or jobs that have a contract as to when the job will end, this is associated with a higher household income than permanent or regular employees. On the other hand, when permanent employment is compared to casual and temporary agency employment, the result shows that permanent employment has a higher household income in comparison to the two mentioned employment (Lab and Wooden, 2020).

According to Bardo et al. (2016), People tend to value a longer working number of hours since it would lead to a greater amount of income which could be a medium of their satisfaction. But at the same time, the study suggests that an increase in income in relation to an extended number of hours would only be applicable to the point that basic needs and necessities are met. For instance, a man who needs money in order to sustain basic needs would prefer to work for an extended period of hours in order 
to have a higher income and when he met those needs, this would result in happiness. If such needs are attained, people tend to be unhappy working for numerous hours even if the income would be relatively higher.

\section{Hypothesis \#3: Employment does not positively affect Total Household Income}

\subsection{Synthesis}

Rural development of an area is very broad in terms of what it may affect and how it will benefit an area. In this research paper, the researchers would like to know if it is possible for an area to be developed but not affect the culture of its indigenous population.

Aetas consists of $14 \%$ of the population in the Philippines. They're the most disadvantaged social group and the poorest. Indigenous people are the descendants of the inhabitants of a country or a region. They have a strong desire to keep their tradition and culture and inherit it to the future generation (Balilla, 2013). Due to this, the researchers would like to figure out if the indigenous people can benefit from developments. The researchers thought that to end the poverty the Aeta communities experience, they could be employed in the establishments being developed in the rural areas for them not to migrate anymore. First, they should be educated and trained properly.

Modernization impacted the indigenous people over the years of development. As Urbanization takes place, the indigenous people's culture and home were also being threatened to leave them with no choice but to migrate from their respective homes to other places (Ting et al., 2008). Until the establishment of the Republic Act No. 8371 (an act to recognize, protect, and promote the rights of indigenous cultural communities/indigenous peoples' rights, create a national commission on indigenous peoples, establish implementing mechanisms, and appropriate funds therefor, and for other purposes.) the indigenous people continued to fight for their rights until now (Ting et al., 2008). Projects and programs were being implemented and continued, which can help the indigenous people to adapt to the fast-changing development, prioritizing the most affected people of many indigenous tribes (Aziz, 2012).

Vulnerability to natural disasters and accessibility to education and health care are the social factors that indigenous people living in rural areas experience and suffer. Tupoula (2007) believes that being out of reach serves as the biggest hindrance to community development since limited political power binds these individuals to unite and adopt a political system and elect a leader who could help the situations they face. The same goes with the study of Licen et al. (2002) in Zambales, Philippines, that the belief of politics has a huge factor in resolving and improving the everyday problems these indigenous people encounter. The Aeta community in Zambales values education so much due to the fact that it would serve as a tool in order to attain political power in order to select the correct officials. Aside from the mentioned problems faced by indigenous people in rural areas, another concern is migration due to the development done by non-indigenous people in the area. According to Tupoula (2007), indigenous people are often discriminated against, which is why identity and culture might be lost. With that being said, the researchers wanted to figure out if migration could be avoided and, at the same time, the indigenous people, particularly the Aetas, would receive benefits from the government and at the same time be employed.

Family Income and Expenditure Survey (FIES) is statistical data conducted and released every three years to gather information on the sources of income, the distribution of income, levels of spending patterns, and the degree of inequality among families. Research from Albert et al. (2007) stated that a study from Tabunda and Albert (2002) used the data from the 1997 (FIES) to analyze the vulnerability of per capita incomes of 11,723-panel households. Proving that the methodology used to determine the Total Household Income is based on this data gathering method.

\section{Hypothesis\#1 Urban amenities does not positively affect Total Household Income}

The study of Liao and Wang (2019) proves that migrants choose to live and work in cities with access to basic amenities such as abundant educational resources, medical resources, and convenient transportation. According to Couture et al. (2018), a research study showed that an increase in income levels is a factor that leads to a huge increase in the population living with urban amenities. As the rich become richer, the demand for amenity development and luxury amenities also increases, leading to a negative outcome that worsens richer households. A research study showed that when richer households with incomes rise, they are more likely to relocate downtown, where the neighborhood landscape improves. A research model conducted by Couture et al. (2018) determined that in the last two decades of research-rich households tend to relocate and live in an area with accessible urban amenities, forcing Urbanization for rural areas to develop and create their own. Several studies showed that indigenous people lack access to basic amenities such as health and knowledge towards correct hygiene behavior Balilla et al. (2014). Low-income families keep their own old traditional ways of herbal treatment in place of advanced health treatment compared to those middleincome class families who have access to it. Some indigenous people do not have access to clean water but only rely on rivers and 
springs (Yang et al., 2020). A study conducted by Zhang and Pyrce (2019) found that income disparities affect the accessibility of urban amenities in poor areas.

\section{Hypothesis \#2: Migration does not positively affect Total Household Income}

There are a lot of studies that showed that there is an increase in rural incomes due to Migration (Rozelle et al., 1999; Taylor et al., 2003; Zhu \& Luo, 2010). Remittances of the migrants is a significant contributor to rural household income growth (De Brauw et al., 2002). In China, if there is an increase in rural-urban migration, there would also be an increase in average rural income. (Howell, 2012). Through non-experimental methods, the income gains from migrations are around 9 to 82 percent (Mckenzie et al., 2010).

\section{Hypothesis \#3: Employment does not positively affect Total Household Income}

As stated in the article by Pearson and Daff (2010), indigenous people living in remote areas have less access to education, resulting in high unemployment. The study suggests that education is much needed because it can improve socioeconomic status and employment for indigenous people. Employment directly indicates household income since employment could be reflected by family income, which was evident in African and Hispanic racial groups in 2010 due to the high level of unemployment, according to Conger et al. (2010). When it comes to the type of job an individual has, a study by Lab and Wooden (2020) shows that as you work more, your income becomes higher in comparison to part-time employment with less income. In conclusion, we could therefore say that employment has a positive and direct effect on total household income.

\section{Methodology}

This chapter presents the methods that were used in conducting the study. It is divided into sections: (3.1) research design; (3.2) scope; (3.3) limitation; (3.4) selection process of the respondents; (3.5) data gathering procedure; (3.6) survey questionnaire the questions came from different studies, but most of the questions came from the World Bank's Living Standard Measurement Survey (LSMS), Demographic and Health Surveys (DHS) and Family Income and Expenditure Survey (FIES)

\subsection{Research Design}

This study used primary data that was gathered through a survey by having a questionnaire that is a combination of the World Bank's Living Standard Measurement Survey (LSMS), Demographic and Health Surveys (DHS), and Family Income and Expenditure Survey (FIES). Through the survey, it was measured if Total household income affects Migration, Employment, and Urban Amenities. The researchers are interested in this topic because the researchers think that indigenous people can be added to the workforce. A development plan could assist and improve their way of living without affecting their culture.

\subsection{Scope of the Study}

The researchers' dependent variable is Total Household Income, and the independent variables are Urban Amenities, Migration, and Employment. To measure these variables, the researchers used the World Bank's Living Standard Measurement Survey (LSMS), Demographic and Health Surveys (DHS), and Family Income and Expenditure Survey (FIES).

The first independent variable is Urban Amenities, which is the access to electricity, water and how advanced they live in terms of material objects they own such as cell phones, television, etc. The second independent variable is migration which is about how many people exit their place or leave their place to find a living or due to land rights. The third independent variable is employment. The researchers wanted to know how many of them are working and how many of them are looking for a job or trying to find a way to earn money.

The researchers decided to survey household heads since they were the best ones who could answer the survey. If two families are residing in one house, then the decision-maker, the one who earns money, and the one who leads the household, is the household head.

\subsection{Limitations of the Study}

The study mainly focuses on the impact of Urbanization on the indigenous people in terms of access to urban amenities, employment, migration, and their income; it does not cover any additional cultural or traditional background of the Aetas, which may derail the main topic of the study into focusing on the historical and cultural lives of these indigenous people back then instead. Another limitation is that the basis of the study is only conducted within the indigenous community residing in Porac, Pampanga.

The researchers also find the timing of the study difficult, especially during this time of the Covid-19 Pandemic. The researchers followed safety protocols such as social distancing and wearing the proper gear before interacting with the respondents. The 
researchers observed proper health precautions, for they were the only ones authorized to write on the questionnaires provided to minimize contact with the respondents. The study was conducted when the city lockdown was lifted.

\subsection{Selection Process}

As per the Selection Process, the Convenience Sampling method was used to select households for the data gathering. Only the nearby households were considered to be interviewed since some of the houses are far. In addition, qualified respondents willing to partake in the interview should be the household heads. In selecting the research field, Barangay Sapang Uwak, Sitio Pidpid, Porac, Pampanga, a gatekeeper was present to assist the researchers. The said gatekeeper is part of a non-governmental organization that helps the Aeta People in Porac, Pampanga, develop their water source.

\subsection{Data Gathering Procedure}

Data Gathering Procedure was done through an interview with a guide of a Survey Questionnaire (See 3.6 for the complete list of questions). A total of 100 participants were present during the said data gathering. The primary respondents in answering the interview are the head or a representative of an Aeta Household in Barangay Sapang Uwak, Sitio Pidpid, Porac, Pampanga, who were present at the time where the data collection was conducted. In order to maintain accuracy, although a Survey Questionnaire was present, the researchers opted for a house-to-house interview since some of the respondents could not read nor write. The data sampling method of purposive sampling was used with the criteria of respondents being a part of the community and interviewing the household head or a representative who has an idea of household expenses and decision making. Cross-sectional data analysis was used to analyze the collected data because it fits a discrete orientated questionnaire, unlike time series that follow a yearly and continuous trend.

In addition to that, the researchers encoded the conversation of the respondents who answered the said questionnaire. The researchers wanted to figure out the relationship of Household Income per Capita to Urban Amenities, Migration, and Employment, which was the primary focus of this study. That is why the questions for the survey were formed in such away. Demographics questions that give a brief background of the respondents were also presented in the survey to assure that the chosen participants are fit to respond for the study.

\subsection{Survey Questionnaire}

1. Number of Household Members:

2. Age:

3. Gender

$$
\begin{array}{ll}
\square & \text { Male } \\
\square & \text { Female }
\end{array}
$$

4. Civil Status:
a Single
$\square$ Married
- Widowed

Note: The next part of the questionnaire was adapted from Living Standards Measurement Study and Demographic and Health Services

\section{URBAN AMENITIES:}
1- Not Important at all
2- Slightly Important
3- Moderately Important
4- Very Important 5- Extremely Important

1.How Important is Transportation in the Community?

\section{Mode of Transportation being used?}

\section{MIGRATION}

1. Is there a family who migrated?
$\square$ Yes
$\square \quad$ No

2. Move to get a job?

$\square$ Yes

$\square \quad$ No

$\square$ Other

3. Remittances Received by the Migrants to their families? 
4. Reason for living in the current residence?

5. Do you receive any kind of financial assistance from the government or help centers?

$\square$ Yes

\section{EMPLOYMENT}

1. Employed or Unemployed

$\square$ Yes

$\square \quad$ No

2. Type of job

$\square$ Agricultural

$\square$ Service

$\square$ Industrial

3. Hours of work daily

4. Occupation (Income Source):

Total Household Income

1. Can you afford to buy basic necessities?

$\square$ Yes

$\square \quad$ No

2. Do you still have any other sources of income aside from your job?

$\square$ Yes

$\square \quad$ No

3. How much do you earn every day?

4. How much is your daily expenses?

\subsection{Regression model}

Total Household Income $=$ B0+ 31 Urban Amenities + B2 Migration + B \Employment $+\mathrm{e}$

\subsubsection{Multiple Regression Model}

Multiple Regression model will be used in order to estimate the relationship between the Dependent variable of Total Household Income and the Independent variables in the study, which are Urban Amenities, Migration, and Employment.

Regression analysis is a statistical technique for estimating the relationship between variables that have a cause-and-effect relationship. Regression analysis is used to determine the correlations between two or more variables with case-effect relationships and make predictions for the topic using the relationship (Unyanik and Guler, 2013).

According to Catalina et al. (2012), one of the most used statistical tools for the relationship between variables is Regression Analysis, and its goal is to look for the right mathematical model and to distinguish the best fitting coefficients for the model. Multiple Regression shares the presumption of correlation in terms of linearity relationship, the same level of relationship throughout the range of the independent variable, interval or near-interval data, outliners being absent, and non-truncated data range.

\section{Results and Discussion}

This section is a comparative or descriptive analysis based on the study results, previous literature, etc. The results should be offered in a logical sequence, given the most important findings first and addressing the stated objectives. The author should deal only with new or important aspects of the results obtained. The relevance of the findings in the context of existing literature or contemporary practice should be addressed.

\subsection{Results}

A sample of one hundred (100) respondents from different representatives of an Aeta Household in Barangay Sapang Uwak, Sitio Pidpid, and Porac in Pampanga took part in conducting this study on how indigenous communities cope with the changes and developments in their community. Among the 100 respondents, Table 1 shows that $81 \%$ were female, and $19 \%$ were male. Figure 2 also reveals that most of the respondents are female. 


\begin{tabular}{|l|l|l|}
\hline Gender & Count & Percent \\
\hline Male & 19 & $19 \%$ \\
\hline Female & 81 & $81 \%$ \\
\hline Total & 100 & $100 \%$ \\
\hline
\end{tabular}

Table 1: Gender

Figure 2: Gender

Table 2 shows that majority were aged 20 to 29 years old (28\%) while the other with less than 20 years old are $12 \%, 30$ to 39 years old are $22 \%, 40$ to 49 years old are $15 \%, 50$ to 59 years old are $9 \%, 60$ to 69 years old are $8 \%$, and 70 years old and above are $4 \%$. Figure 3 also reveals that most of the respondents are 20 to 29 years old.

\begin{tabular}{|l|l|l|}
\hline Age & Count & Percent \\
\hline Less than 20 & 12 & $12 \%$ \\
\hline 20 to 29 & 28 & $28 \%$ \\
\hline 30 to 39 & 22 & $22 \%$ \\
\hline 40 to 49 & 15 & $15 \%$ \\
\hline 50 to 59 & 9 & $9 \%$ \\
\hline 60 to 69 & 8 & $8 \%$ \\
\hline 70 and above & 4 & $4 \%$ \\
\hline NA & 2 & $2 \%$ \\
\hline Total & 100 & $100 \%$ \\
\hline
\end{tabular}

Table 2: Age

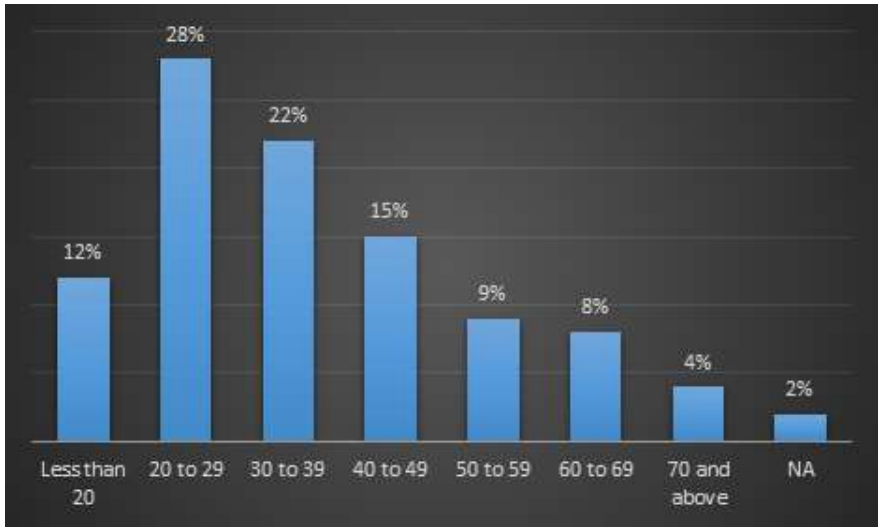

Figure 3: Age

Table 3 shows that the majority of the respondents have 3 to 4 family members (41\%) while the others with 1 to 2 members are $22 \%, 5$ to 6 members are 25 or $25 \%, 7$ to 8 members are $11 \%$, and 8 to 10 members are $1 \%$. Figure 4 also reveals that most of the respondents have 3 to 4 family members.

\begin{tabular}{|l|l|l|}
\hline No. of Household Members & Count & Percent \\
\hline 1 to 2 & 22 & $22 \%$ \\
\hline 3 to 4 & 41 & $41 \%$ \\
\hline 5 to 6 & 25 & $25 \%$ \\
\hline 7 to 8 & 11 & $11 \%$ \\
\hline 8 to 10 & 1 & $1 \%$ \\
\hline Total & 100 & $100 \%$ \\
\hline
\end{tabular}

Table 3: Number of Household

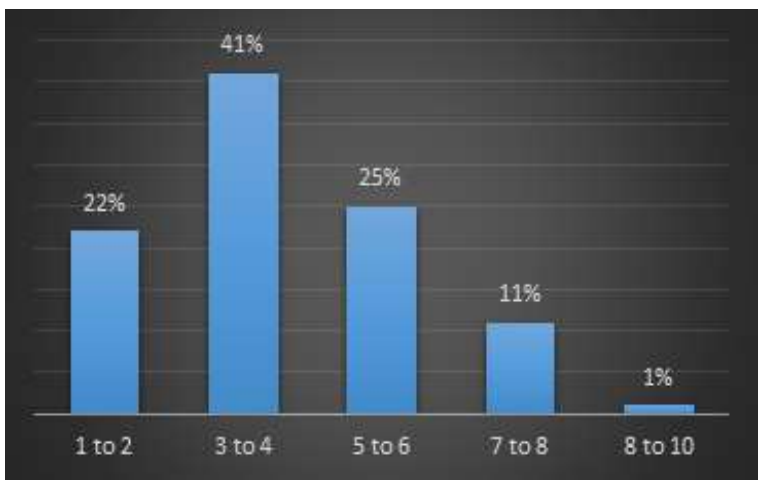

Figure 4: Number of Households 
Table 4 shows that most of the respondents are married (93\%), while the single respondents are $5 \%$, and widowed respondents are $2 \%$. Figure 5 also reveals that most of the respondents are married.

\begin{tabular}{|l|l|l|}
\hline Civil Status & Count & Percent \\
\hline Single & 5 & $5 \%$ \\
\hline Married & 93 & $93 \%$ \\
\hline Widowed & 2 & $2 \%$ \\
\hline Total & 100 & $100 \%$ \\
\hline
\end{tabular}

Table 4: Civil Status

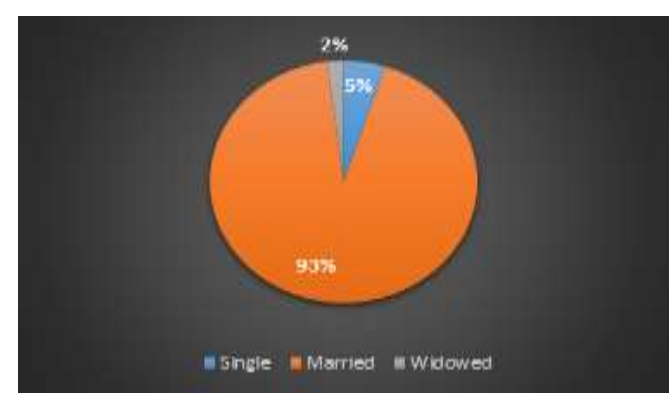

Figure 5: Civil Status

Table 5 shows that respondents with migrated families are 53\%, while those without are $47 \%$. Figure 6 also reveals that the majority of the respondents have migrated families.

\begin{tabular}{|l|l|l|}
\hline Family who Migrated & Count & Percent \\
\hline Yes & 53 & $53 \%$ \\
\hline No & 47 & $47 \%$ \\
\hline Total & 100 & $100 \%$ \\
\hline
\end{tabular}

Table 4: Migrated Families

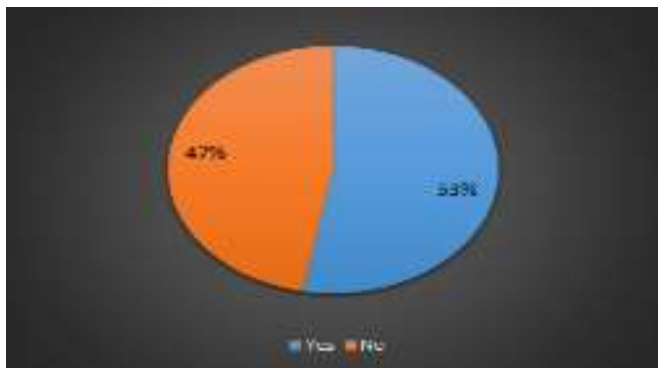

Figure 5: Migrated Families

Table 6 shows that the majority of the respondents who did not relocate for a job are $69 \%$, while those who relocated for a job are $16 \%$, and $15 \%$ were IPRA. Figure 7 also reveals that most of the respondents did not relocate for a job.

\begin{tabular}{|l|l|l|}
\hline Move for a Job & Count & Percent \\
\hline Yes & 16 & $16 \%$ \\
\hline No & 69 & $69 \%$ \\
\hline IPRA & 15 & $15 \%$ \\
\hline Total & 100 & $100 \%$ \\
\hline
\end{tabular}

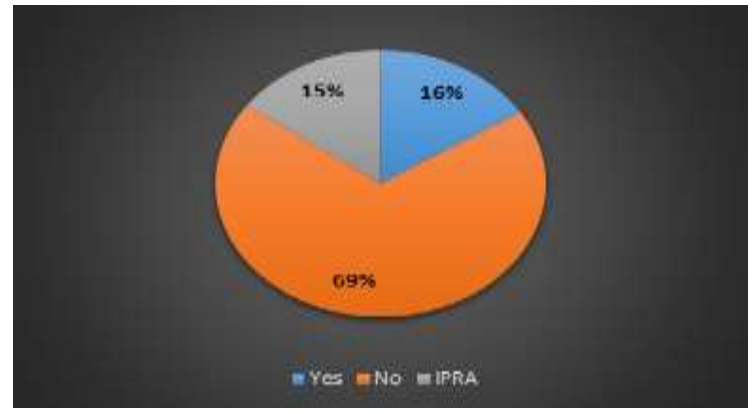

Figure 7: Relocated for a Job

Table 6: Relocated for a Job 
Table 7 shows that the majority of the respondents who do not receive any remittances are at $96 \%$, while the others who receive only 500 pesos are $2 \%$, and with both 2000 and 4000 pesos are 1 or $1 \%$. Figure 8 also reveals that most of the respondents do not receive remittances.

\begin{tabular}{|l|l|c|}
\hline Remittances Received & Count & Percent \\
\hline Php 0 & 96 & $96 \%$ \\
\hline Php 500 & 2 & $2 \%$ \\
\hline Php 2000 & 1 & $1 \%$ \\
\hline Php 4000 & 1 & $1 \%$ \\
\hline Total & 100 & $100 \%$ \\
\hline
\end{tabular}

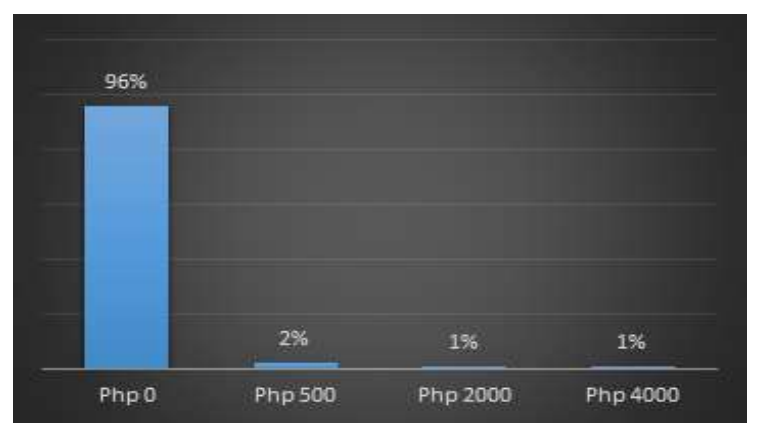

Figure 8: Remittances Receive

Table 8 shows that most of the respondents' reason for living in their current residence is because of their ancestral land (66\%), because of marriage at $22 \%$, because of work are $4 \%$, and because of the spouse's job 1 or $1 \%$. Figure 9 also reveals that most of the respondents are living in their current residence because it's their ancestral land.

\begin{tabular}{|l|l|l|}
\hline Reasons for Living & Count & Percent \\
\hline Ancestral Land & 66 & $66 \%$ \\
\hline Marriage & 29 & $29 \%$ \\
\hline Work / Job & 4 & $4 \%$ \\
\hline Job of Spouse & 1 & $1 \%$ \\
\hline Total & 100 & $100 \%$ \\
\hline
\end{tabular}

Table 8: Reason for Living

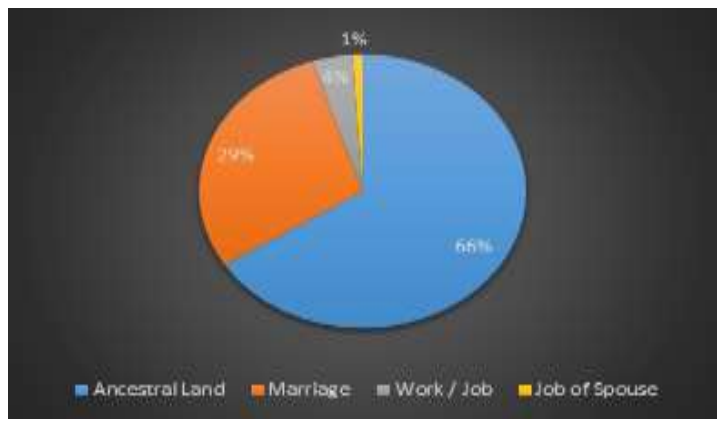

Figure 9: Reason for Living

Table 9 shows that most of the respondents received government funds at $96 \%$ while the others did not receive any funds at 4 or $4 \%$. Figure 10 also reveals that most of the respondents receive government funds.

\begin{tabular}{|l|l|l|}
\hline Received Govt Fund & Count & Percent \\
\hline Yes & 96 & $96 \%$ \\
\hline No & 4 & $4 \%$ \\
\hline Total & 100 & $100 \%$ \\
\hline
\end{tabular}

Table 9: Received Govt Funds

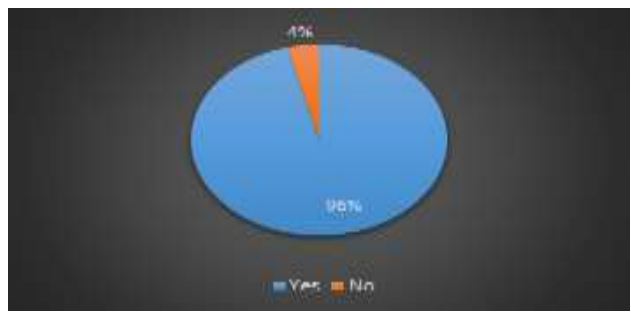

Figure 10: Received Govt Funds

Table 10 shows that most of the respondents who migrated are employed (94\%), and some are not employed (6\%). Figure 11 also reveals that most of the respondents are employed. 


\begin{tabular}{|l|l|l|}
\hline Employed & Count & Percent \\
\hline Yes & 94 & $94 \%$ \\
\hline No & 6 & $6 \%$ \\
\hline Total & 100 & $100 \%$ \\
\hline
\end{tabular}

Table 10: Employment

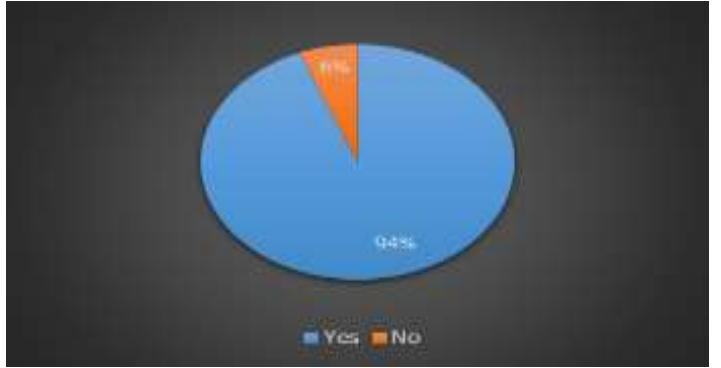

Figure 11: Employment

Table 11 shows that respondents who are employed are working in the field of agriculture are (95\%), and the remaining are not employed (5\%). Figure 12 also reveals that most of the respondents are working in the field of agriculture.

\begin{tabular}{|l|l|l|}
\hline Type of Job? & Count & Percent \\
\hline Agriculture & 95 & $95 \%$ \\
\hline NA & 5 & $5 \%$ \\
\hline Total & 100 & $100 \%$ \\
\hline
\end{tabular}

Table 11: Type of Job

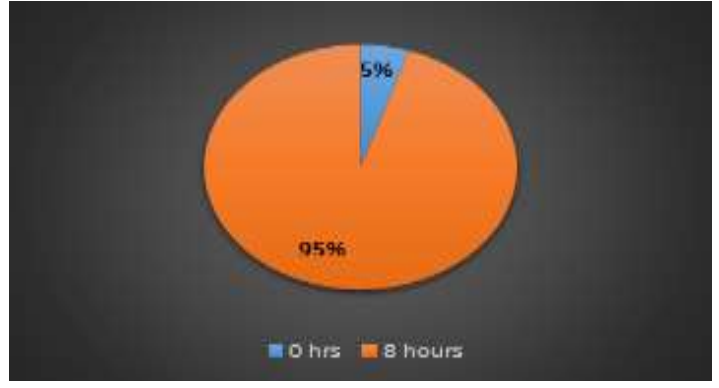

Figure 12: Type of Job

Table 12 shows that most of the respondents have an average of 8 working hours (95\%) daily, and the others who are not employed are $5 \%$. Figure 13 also reveals that most of the respondents are working 8 hours.

\begin{tabular}{|l|l|l|}
\hline Working Hours & Count & Percent \\
\hline 0 hrs & 5 & $5 \%$ \\
\hline 8 hours & 95 & $95 \%$ \\
\hline Total & 100 & $100 \%$ \\
\hline
\end{tabular}

Table 12: Working Hours

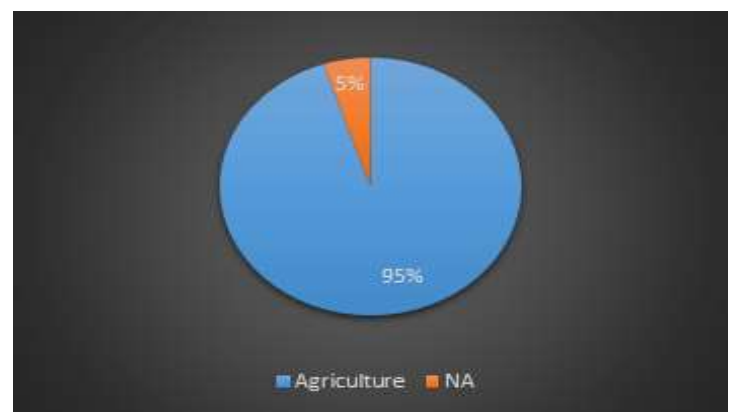

Figure 13: Working Hours

Table 13 shows that the majority of the respondents' earnings with less than 500 pesos are at $85 \%$, while the others who earn with an average of 500 to 1000 pesos are $8 \%, 001$ to 2000 pesos are $5 \%$, and with 2001 to 3000 pesos are 2 or $2 \%$. Figure 14 also reveals that most of the respondents have less than 500 pesos of daily income. 


\begin{tabular}{|l|l|l|}
\hline Daily Earnings & Count & Percent \\
\hline Less than 500 & 85 & $85 \%$ \\
\hline 500 to 1000 & 8 & $8 \%$ \\
\hline 1001 to 2000 & 5 & $5 \%$ \\
\hline 2001 to 3000 & 2 & $2 \%$ \\
\hline Total & 100 & $100 \%$ \\
\hline
\end{tabular}

Table 13: Daily Earnings

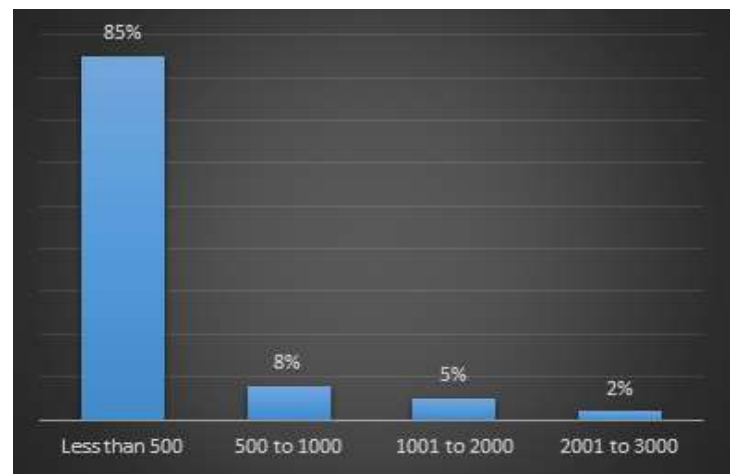

Figure 14: Daily Earnings

Table 14 shows that respondents with less than 500 pesos' daily expenses are $87 \%$, with 500 to 1000 pesos are $10 \%$, and with 1001 to 2000 pesos are $3 \%$. Figure 15 also reveals that most of the respondents have less than 500 pesos of daily expenses.

\begin{tabular}{|l|l|l|}
\hline Daily Expenses & Count & Percent \\
\hline Less than 500 & 87 & $87 \%$ \\
\hline 500 to 1000 & 10 & $10 \%$ \\
\hline 1001 to 2000 & 3 & $3 \%$ \\
\hline Total & 100 & $100 \%$ \\
\hline
\end{tabular}

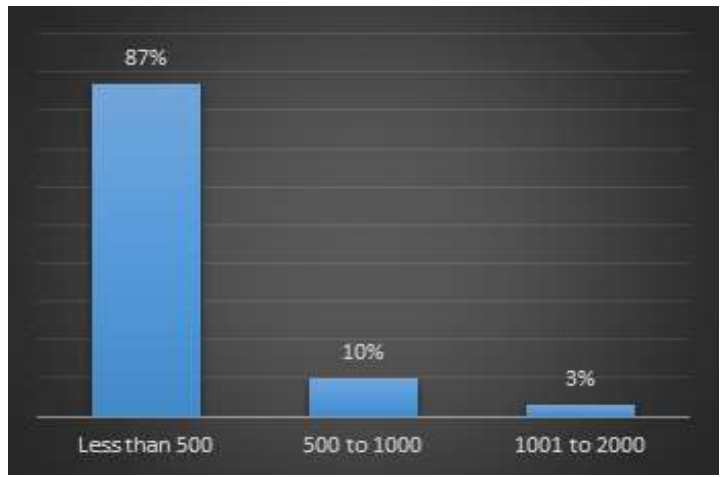

Table 14: Daily Expenses

Figure 15: Daily Expenses

Table 15 indicates the Model Summary that determines if the model given is acceptable. It shows that R has an estimated value of 0.143 with an $\mathrm{R}$-square of 0.021 . Therefore, employment and migration can explain $2.1 \%$ of the variability of monthly income. Table 15: Model Summary

\begin{tabular}{|l|l|l|l|l|}
\hline Model & R & R Square & Adjusted R Square & Std. Error of the Estimate \\
\hline 1 & $0.143^{a}$ & 0.021 & 0.000 & 518.575 \\
\hline
\end{tabular}

a. Predictors: (Constant), Employment, Migration

Table 16 shows that $F=1.017$ with $p$-value $=0.365$. Since the $p$-value is greater than 0.05 , the null hypothesis cannot be rejected and the researchers conclude that employment and migration have no significant relationship to income.

Table 16: ANOVA ${ }^{b}$

\begin{tabular}{|l|l|l|l|l|l|l|}
\hline \multicolumn{2}{|l|}{ Model } & Sum of Squares & df & Mean Square & F & Sig. \\
\hline 1 & Regression & 547169.950 & 2 & 273584.975 & 1.017 & $0.365^{a}$ \\
\cline { 2 - 7 } & Residual & $2.609 E 7$ & 97 & 268919.897 & & \\
\cline { 2 - 7 } & Total & $2.663 E 7$ & 99 & & & \\
\hline
\end{tabular}

a. Predictors: (Constant), Employment, Migration

b. Dependent Variable: Income 
Table 17 below shows the summary that migration $(t=0.041, p=0.968)$ and employment $(t=1.415, p=0.160)$ have $P$-values greater than 0.05 , thus the Ho is accepted. Therefore, migration and employment have no significant effect on the income of respondents.

Table 17: Coefficients

\begin{tabular}{|l|l|l|l|l|l|l|}
\hline \multicolumn{2}{|l|}{} & \multicolumn{2}{|l|}{$\begin{array}{l}\text { Unstandardized } \\
\text { Coefficients }\end{array}$} & \multicolumn{2}{l}{$\begin{array}{l}\text { Standardized } \\
\text { Coefficients }\end{array}$} & Sig. \\
\cline { 2 - 7 } Model & B & Std. Error & Beta & & \\
\hline 1 & (Constant) & -82.782 & 442.627 & & -0.187 & 0.852 \\
\cline { 2 - 7 } & Migration & 4.242 & 104.421 & 0.004 & 0.041 & 0.968 \\
\cline { 2 - 7 } & Employment & 310.460 & 219.450 & 0.143 & 1.415 & 0.160 \\
\hline
\end{tabular}

a. Dependent Variable: Income

\subsection{Discussion}

The main objective of this study is to establish a possible development plan in the rural community and, at the same time, not harm the Aeta community's culture would be possible. This study used primary data that was gathered through a survey by having a questionnaire that is a combination of the World Bank's Living Standard Measurement Survey (LSMS), Demographic and Health Surveys (DHS), and Family Income and Expenditure Survey (FIES). The survey will be measured if Total household income affects Migration, Employment, and Urban Amenities. The study's findings revealed a positive result based on the proposed hypothesized model. Among all the supported relationships, Employment and Migration do not have a significant effect on the Total Household Income.

The study's findings indicate how indigenous communities cope with the changes and developments in society. First, the variable Urban Amenities do not affect the variable Total household Income. Based on the data collected by the researchers, urban amenities greatly affect the total income of the indigenous people; it is stated that transportation is extremely important in their daily life, and also motor sidecars are their main mode of transportation. According to the American Community Surveys (ACS) data, ranging from 2011-2015, as the income of the rich rises, so does their desire for more advanced urban amenities, leading them to choose to live in downtown urban areas to be closer to these urban amenities. The in-migration of higher-income individuals increases downtown rents, resulting in a financial externality for low-income residents in downtown urban areas. Thus, urban amenities affect the total income and the quality of life of an individual, leading to the intention to migrate.

Second, the results of the data validated the second hypothesis, which stated that migration does not affect the Total Household income of the indigenous people. According to (Ajaero 2013), rural-urban migrants send remittances in different forms such as money, food, and clothing at a definite interval, commonly once a month. Furthermore, the migrants execute development projects in their rural communities of origin, which leads to socioeconomic development. Their remittances promote people's pleasure and satisfaction while also improving the population's quality of life and well-being. Therefore, migration does not affect the total income of indigenous people since they make migration decisions wherein they can maximize the expected present value of their income.

Lastly, the variable employment does not affect the variable total household income. The study findings found an insignificant relationship between employment and total household income. Thus, most of the indigenous people who migrated are employed and working in the agriculture field. According to (Lab and Wooden, 2020), when it comes to employment and household income, those with temporary work tend to pay less, which would negatively impact household income. Working fewer hours would result in lower wages. When compared to permanent or regular employees, fixed-term employment or positions with a contract specifying when the job will terminate relates to a higher household income.

\section{Conclusion}

This research aims to assess the impact of Urbanization on the indigenous group of people in Pampanga. Indigenous people are also referred to as the people whose ways of living are different from mainstream society. Since Urbanization is inevitable due to modernization, not all people can get through the changes around them. The variables migration, employment, and urban amenities were used to show each significance on the total household income of indigenous people. The results revealed that all 
these three variables - urban amenities, migration, and employment - do not affect the total household income, as evidenced by their statistical insignificance. Care could have been exercised in the planning and providing resettlement sites for indigenous people even though the results showed an insignificant relationship.

The aim of this study is to determine whether the three variables: Urban Amenities, Migration, and Employment affects the Total Household Income. The researchers found out that only one variable, Urban Amenities, greatly affects the Total Household Income. While the other two variables, Migration, and Employment, did not affect the said dependent variable.

Liang and Wang (2019) stated that several studies prove the importance of access to urban amenities to the well-being of an individual, especially rural-urban migrants; the researchers found the statement to be true. As the income rises, the desire for urban amenities also rises. Income is a huge factor that affects the quality of life, especially the modern technologies that the people have right now and also with regard to transportation.

According to Rozelle et al. (1999), Taylor et al. (2003), and Zou \& Luo (2010), there is an increase in rural income due to migration, but the result of this study did not support this claim. There is no significant relationship between Migration and Total Household Income. This can be concluded that as they migrate, it will not affect their income; they can still send remittances in different forms such as money and food, etc.

Also, the variable employment has no significant relationship to their Total Household Income. Lab and Wooden (2020) stated that as you work more, your income becomes higher in comparison to those with part-time employment who have less income. This can be assumed that it has a great and direct effect on the Total Household Income, but the researchers' results do not support this statement.

This study's findings will help people understand and have more knowledge about the rapid adaptation of indigenous people to Urbanization. To sum up, only Urban Amenities affect the income of our indigenous people. Living or migrating in urban areas increases the expenses of the indigenous people because they have different ways of living.

Funding: This research received no external funding

Acknowledgments: This research was done through the generous and endless support of our family, friends, and professors. First and foremost, we thank the Almighty Father for providing us with the strength to write this thesis. We also like to express our utmost gratitude to Asst. Prof. Marie Antoinette L. Rosete, MDE, our research adviser, for her consistent guidance and for motivating us all throughout our research. We would also like to thank the Business Economics Department of the University of Santo Tomas for this opportunity.

Conflicts of Interest: The authors declare no conflict of interest.

\section{References :}

[1] Albert J.R, Elloso, L.V. \& Ramos A.P. (2007) Toward Measuring Household Vulnerability to Income Poverty in the Philippines. Philippine Institute for Development Studies. Philippine Institute for Developing Studies (PIDS), Government of the Philippines

[2] Ajaero, C.K, \& Onokala, P.C, (2013) The Effects of Rural-Urban Migration on Rural Communities of Southeastern Nigeria," International Journal of Population Research, vol. 2013, 10 pages, 2013.

[3] Amuakwa-Mensah, Boakye-Yiadom, Louis., \& Baah-Boateng, W. (2016) Effect of education on migration decisions in Ghana: a rural-urban perspective, Journal of Economic Studies,

[4] Aziz N.N., Wan Hassan, W.H. \& Saud, N.A. (2012). The Effects of Urbanization towards social and cultural changes among Malaysian Settlers in the Federal Land Development Schemes (FELDA), Johor Darul Takzim. Procedia - Social and Behavioral Sciences

[5] Balilla, V. S., Mchenry, J. A., Mchenry, M. P., Parkinson, R. M., \& Banal, D. T. (2013). Indigenous Aeta Magbukún Self-Identity, Sociopolitical Structures, and Self-Determination at the Local Level in the Philippines. Journal of Anthropology, 2013, 1-6.

[6] Bardo, A.R., Liu, D. \& Yamashita, T. (2016). Are East Asians happy to work more or less? Associations between working hours, relative income, and happiness in China, Japan, South Korea, and Taiwan. Asian Journal of Social Psychology, 19(3), 264-274.

[7] Catalina, T., Caracaleanu, B., \& lordache, V. (2012). Multiple Regression model for fast prediction of heating energy demand. Energy and Buildings, 57, 302-312.

[8] Chaolin, GU (2020) International Encyclopedia of Human Geography (Second Edition).

[9] Codjoe, S. N. A. (2006). Migrant versus indigenous farmers. An analysis of factors affecting agricultural land use in the transitional agroecological zone of Ghana, 1984-2000. Geografisk Tidsskrift-Danish Journal of Geography, 106(1), 103-113.

[10] Conger, R. D., Conger, K. J., \& Martin, M. J. (2010). Socioeconomic Status, Family Processes, and Individual Development. Journal of Marriage and Family, 72(3), 685-704.

[11] Couture. (2018). Income Growth and the Distributional Effects of Urban Spatial Sorting. National Bureau of Economic Research,

[12] De Vera, E. (2007) Indigenous Peoples in the Philippines: A Country Case Study.Philippine Association for Inter-Cultural Development Inc.

[13] Domingo, S.N. \& Manejar A.J.A. (2020). Review of Indigenous Peoples Policy and Institutional Grounding. Discussion Paper Series No.2020-20. 
[14] Duijin, M. (2014) Model of household location and urban amenities. University of Amsterdam

[15] Fa, J., Watson, J., Leiper, I., Potapov, P., Evans, T., Burgess, N., Molnár, Z., Fernández-Llamazares, A., Duncan, T., Wang, S., Austin, B., Jonas, H., Robinson, C., Malmer, P., Zander, K., \& Jackson, M., Ellis, E., Brondizio, E., \& Garnett, S. (2020). Importance of Indigenous Peoples' lands for the conservation of Intact Forest Landscapes. Frontiers in Ecology and the Environment.

[16] Fisher, M., Reimer, J. J., \& Carr, E. R. (2010). Who Should be Interviewed in Surveys of Household Income? World Development, 38(7), 966-973.

[17] Howell, A. (2017). Impacts of Migration and Remittances on Ethnic Income Inequality in Rural China. World Development, 94, $200-211$.

[18] Jaumotte, F., Koloskova, K., \& Saxenav S. (2016), Impact of Migration on Income Levels in Advanced Economies. International Monetary Fund

[19] Kennan \& Walker (2011) The effect of expected income on individual migration decisions. (2011). Econometrica, 79(1), 211-251

[20] Laß, I., Wooden, M. (2020). Temporary Employment Contracts and Household Income. Soc Indic Res 147, 111-132.

[21] Liao L, Wang C (2019) Urban amenity and settlement intentions of rural-urban migrants in China. PLOS ONE 14(5)

[22] Licen, N., Lihtenvalner, K., \& Podgornik, V. (2012). The non-formal education and migration of the Aeta, an indigenous tribe in the Philippines. Anthropological Notebooks. 18. 25-40.

[23] McDonell, S., Allen M.G., \& Filer, C. (2017). Kastrom property and ideology land transformations.Melanesia ANU Press.

[24] Mckenzie, D., Stillman, S., \& Gibson, J. (2010). How Important is Selection? Experimental VS Non-Experimental Measures of the Income Gains from Migration. Journal of the European Economic Association, 8(4), 913-945.

[25] Ortega, F., \& Peri, G (2014) Openness and income: The roles of trade and migration. Journal of International Economics, 92(2), $231-251$.

[26] Pearson, C. A. L., \& Daff, S. (2010). Education and Employment Issues for Indigenous Australians in Remote Regions. Journal of Human Values, 16(1), 21-35.

[27] Republic Act, 8371 (1997). The Indigenous Peoples Rights Act of 1997. Official Gazette of the Republic of the Philippines

[28] Rogayan Jr, D. (2019). Dilemmas encountered by Aeta students in a state university in Central Luzon, Philippines. Journal of Humanities and Education Development. 1. 233-239.

[29] Ting. (2008). Modernity vs. Culture: Protecting the Indigenous Peoples of the Philippines. European Journal of Economic and Political Studies

[30] Tupuola, A. (2007). Urban Indigenous Peoples and Migration. United Nations Headquarters in New York 14-25 May.

[31] Uyanik \& Guler (2013) A Study on Multiple Linear Regression Analysis. Procedia - Social and Behavioral Sciences 106:234-240

[32] Yang. (2020). A study on health and hygiene needs, strategies, and well-being of an Aeta indigenous community in the Philippines through photovoice methods. Asian Social Work and Policy Review, 126-137

[33] Zabala, B. (2018). The Migrated Indigenous People (AETAS). International Journal of Humanities and Social Science. 3.

[34] Zhang \& Prcye (2019) The dynamics of poverty, employment and access to amenities in polycentric cities: Measuring the decentralization of poverty and its impacts in England and Wales. Urban Studies, 1-16 